\title{
Cultivating Community: Presentation of Self among Women Game Streamers in Singapore and the Philippines
}

\author{
Katrina Paola B. Alvarez \\ Wee Kim Wee School \\ of Communication \& Information \\ Nanyang Technological University \\ kpbalvarez@gmail.com
}

\author{
Vivian Hsueh-hua Chen \\ Wee Kim Wee School \\ of Communication \& Information \\ Nanyang Technological University \\ ChenHH@ntu.edu.sg
}

\begin{abstract}
This study explored how women game live streamers in Singapore and the Philippines make sense of their presentation of self as performers and gamers in a medium dominated by Western games, performers, and platforms. We conducted six in-depth interviews guided by interpretive phenomenological analysis in order to understand their experiences, uncovering issues such as audience connection and maintenance, the difficulties of presenting their own femininity, and the influence of being Singaporean, Filipina, and Asian on their success as performers. We discuss directions for study that further explore gaming and streaming as a form of cultural labor in Asia.
\end{abstract}

\section{Introduction and Literature Review}

People have been watching others play video games since the 1980s heyday of public gaming arcades [1][2][3]. In recent years, electronic sports (esports) have helped to revive gaming as a spectator activity on a much larger scale. Global e-sports revenues are expected to reach US\$1.06 billion in 2020, and the coronavirus pandemic has led to increased consumption of game live streams as audiences look for more content during isolation or quarantine [4]. Such live streams, where both professional and amateur gamers broadcast their play to possibly thousands of viewers online, engages players and consumers in new ways that potentially reshape other areas of e-sports, such as by disseminating play styles or techniques favored by leading players [5], and the game industry itself, through new forms of game reviewing, marketing, and sharing [6]. At the same time, live streaming is serving as a new form of cultural labor and production [7]. One overlooked area is the cultural labor of women game streamers in Southeast Asia, the world's fastest growing e-sports market in 2019 [8]. This paper explores how women game streamers in Southeast Asia manage their presentation of self [9] while cultivating a stable community of viewers and navigating a medium perceived as dominated by North American and European content creators, in a region whose game industry and culture are also led by foreign games [10][11].

The presentation of self framework proposes that social interactions can be understood as performance. People engage in various practices in order to cultivate, manage, and manipulate others' impressions of them, their actions, and the situation. Often, the performed persona or presented self can be different from the self that has no audience present [9]. As researchers and streamers alike similarly view streaming as a performance [12][13][14][15], streaming offers a new medium in which to study the presentation of self. Past research on online presentation of self has so far focused on asynchronous communication media such as dating websites/applications, blogs, and social networking sites (e.g., [16][17]). Other work explored presentation of self on platforms with some anonymity, such as in forums or message boards, chat rooms, and multiplayer online games, where pseudonyms and avatars represent oneself to others (e.g., [18]). Streaming, where performance is live, interaction with viewers can be immediate, and one's actual face and identity are often visible, is a comparatively new context for examining the online presentation of self.

Social interaction, the scene for any performance, is a primary motivation for viewers and streamers alike. Viewers hope for streamers to respond to their comments or follow one of their gameplay suggestions [15]. They also have opportunities to chat with other viewers who share their interests. Viewers derive status from becoming a stream regular and knowing who's who in a stream community, and a stream can be an important channel for socialization for the physically and/or socially isolated [13]. One study 
Table 1. Background of interview participants

\begin{tabular}{|l|l|l|l|l|l|}
\hline Participant & Nationality & \multicolumn{1}{|c|}{ Occupation } & \multicolumn{1}{|c|}{$\begin{array}{c}\text { Streaming } \\
\text { Platform }\end{array}$} & \multicolumn{1}{|c|}{ Game/Genre } & \multicolumn{1}{|c|}{ E-Sports Role } \\
\hline Jayna & PH & $\begin{array}{l}\text { streaming, family } \\
\text { business }\end{array}$ & Facebook Gaming & $\begin{array}{l}\text { League of } \\
\text { Legends }\end{array}$ & streaming talent \\
\hline Camille & SG & paralegal, student & Twitch & $\begin{array}{l}\text { Fortnite and other } \\
\text { first-person } \\
\text { shooter (FPS) } \\
\text { games }\end{array}$ & n/a \\
\hline Venice & SG & $\begin{array}{l}\text { public relations } \\
\text { executive }\end{array}$ & Twitch & $\begin{array}{l}\text { casual, mobile, or } \\
\text { FPS games }\end{array}$ & $\begin{array}{l}\text { former } \\
\text { professional } \\
\text { player }\end{array}$ \\
\hline Bethany & SG & artist & Twitch & $\begin{array}{l}\text { multiplayer online } \\
\text { battle arena } \\
\text { (MOBA) games }\end{array}$ & streaming talent \\
\hline Wednesday & SG & $\begin{array}{l}\text { streamer } \\
\text { casual or digital } \\
\text { card games }\end{array}$ & streaming talent \\
\hline Noreen & PH & $\begin{array}{l}\text { student, } \\
\text { professional } \\
\text { player }\end{array}$ & Twitch & $\begin{array}{l}\text { League of } \\
\text { Legends }\end{array}$ & $\begin{array}{l}\text { professional } \\
\text { player }\end{array}$ \\
\hline
\end{tabular}

found social motivations to be a key predictor of subscribing to a stream [19].

Past game streaming research has also suggested how streamers engage in impression management practices for successful presentation of self, precisely to attract returning and regular viewers. Streamers see ntial viewers while seeming natural on-camera [14], and a streamer's personality and performance quality may be more important to viewers than actual skill at playing games [12][15]. Even those who stream for the first time, to almost zero viewers, modify their behavior, knowing someone might be watching [20].

Although many streamers enjoy the community and income gained from play, women streamers experience unwanted attention-harassment, sexualization, and objectification - that male streamers do not [21][13]. In general, women e-sports professionals must carefully manage how they present their femininity to avoid such unwanted attention and gain acceptance by the wider community of gamers [22]. The discourse around women streamers' selfpresentation suggests that viewers and fellow streamers alike make sexist judgments regarding their legitimacy and merit as gamers and performers [23]. Even community guidelines set by streaming platform companies themselves attempt to regulate women's self-presentation in ways that might ultimately further their marginalization [24]. How women streamers manage their presentations of self is thus a critical streams as a place to make friends, but they also see themselves as hosts responsible for cultivating a sense of community, by developing a core group of regular viewers/subscribers through interactions [13]. Streamers work to develop specific attitudes that might make them appealing to pote

issue for women hoping to establish their audiences and be accepted by the gaming community.

Most game streaming research so far has focused on streamers and audiences in North America and Europe, and most studies on gaming culture and experience in Asia have tended to center on the three largest markets, China, Japan, and South Korea. This is similar to trends in research on online celebrity in general [25]. In this study, we chose Singaporean and Filipina streamers as participants for their in-between position. They favor Western games in a market dominated by East Asian game products [11] and live in Westernized countries that continue to uphold patriarchal and Asian collectivist ideals of femininity [26][27]. This study aimed to contribute to the still growing body of research on streamers' experiences by seeking them in a new context, using the following research question: how do women streamers in the selected countries manage self-presentation to cultivate desirable relationships to and positions in their communities? 


\section{Methods}

This study was guided by interpretive phenomenological analysis (IPA), which is concerned with understanding participants' lived experiences in their own terms [28]. Unlike grounded theory, which seeks to produce explanations of a phenomenon by identifying its underlying processes, IPA aims for an account of the world as experienced by its participants, whose unique and varying experiences of the chosen phenomenon might yet yield common meanings and themes [29].

We interviewed six women in their early to mid20 s who had been streaming gameplay for approximately one year or more. Four of them were Singaporean, and two, Filipina. Three of them were directly contacted through publicly available email addresses or social media accounts; two, through a public relations officer for their professional e-sports organization; and one, through personal referral in the Singapore e-sports community. The only criteria for selection were the participants' age, sex, and nationality; there were no criteria regarding viewership or status. However, it so happened that most of the participants had prior or current professional e-sports connections, and all had a streaming partnership, which allows a streamer to earn money from streaming and indicates a stable audience [7]. In this paper, the participants' names have been changed for anonymity.

Table 1 provides more detail on the participants' backgrounds at the time of the interviews. We use "streaming talent" to indicate that the participant was on an e-sports organization's official roster of streamers, whereas Noreen was identified as a "professional player" because she not only was a streamer but also represented her organization in official matches.

In semi-structured interviews, we asked the participants about their experiences as streamers, their definitions of success, their goals, and how being women and how their local communities or cultures influenced their experiences. They were interviewed face-to-face, through online voice call, or through email. All participants were interviewed in English, except for Jayna, who preferred a mix of Tagalog and English (Taglish); her quotations have been translated. Some quotations also feature Singaporean English or Singlish colloquialisms.

We also observed participants' live streams as well as those of other Singaporean/Filipina streamers on Twitch and Facebook Gaming. These observations supplemented and contextualized the interview data, which remain the primary focus of this paper.
We followed IPA guidelines for analysis, reading and rereading the transcripts, making descriptive, linguistic, and conceptual comments before making final annotations of emergent and recurrent themes. These themes were extracted and rearranged based on how they related to one another both chronologically and conceptually in the transcripts and emails. This process yielded three higher-level themes tackled in the subsections below: meeting the expectations of their viewing communities, struggling with expectations regarding female streamers, and finding or not finding satisfaction in their reach as Asian streamers.

\section{Analysis and Results}

\subsection{A face for the community}

Asking the streamers how they entered the medium was met with backtracking into their personal histories as gamers. Jayna and Camille both described how they had been playing video games since childhood, Venice brought up her past as a professional player, and Bethany and Wednesday mentioned that they had already been playing or watching a particular e-sports game for fun. Participants were thus drawn to streaming as a new way to share a long-enjoyed pastime or pursuit with like-minded others. While potential income was appealing, community and social interaction with people who might want to share gaming experiences was the main draw. "Ultimately," Bethany said, "I just thought it'd be fun to share my love for games."

Camille, who had a negative initial perception of streaming, even felt that interacting with those first viewers led her to see streaming as a new way to engage with games:

I thought it was very fun, because there were people actually in the chat telling you what to do, or rather, telling you to try this and that. It kinda expanded my game a lot more. From one game, I feel like playing a lot more games, 'cause there's actually a lot more depth to the game. And then I met some friends, probably three, four friends from that one time of streaming, and it made me kinda want to try again.

However, the very communities that participants found through streaming have been sources of tension and stress from the start. As beginners, the streamers felt fear, awkwardness, and apprehension at the thought of being watched and judged. Many participants expressed similar misgivings to Noreen's: "It was scary. I was worried about whether or not 
people like me or find me interesting on my streams. I worried about what people will think of me."

As seasoned performers, these initial feelings have evolved into a sense of obligation to consistently meet viewers' expectations regarding interaction and engagement. Exchanging greetings in particular took up a lot of attention, as noted in previous work [7]. In our observations, only a few viewers attempted to sustain conversations with the streamer and with other viewers; most were silent or offered a quick greeting before continuing to spectate quietly. The streamers seemed to recognize that greetings might thus be the only interaction they might have with a particular viewer and consistently attempted to greet everyone who commented during streams. A greeting was a small thing a streamer could do to possibly gain a new viewer's loyalty, which could boost the quantitative metrics by which the streamers measured success.

Jayna's thoughts below capture how important greetings are to a streamer's self-presentation in response to perceived expectations.

I don't want anyone to say, "Oh, she's such a snob! Oh, she's so crabby!" I don't want anyone to be saying this, so even if I'm playing a ranked game, definitely, my eye is always going to the comment section. Sometimes, I'm late, but I haven't skipped a comment, because I don't want them to feel they aren't welcome, or that I don't feel their presence.

The participants took various approaches when it came to engaging audiences with gameplay itself. Camille, Noreen, and Jayna scheduled multiplayer cooperative games with viewers, for example. Venice and Wednesday played single-player games but made more commentary and conversation.

Regardless of stream content, participants perceived they were expected to perform consistently. Thus, they often felt that an on-camera persona was necessary. This persona was usually someone upbeat and fun to watch playing or to play with, regardless of what was going on in her off-stream life. Venice, for example, described her persona as a separate person: "She's the face, and there are a lot of things behind the face that people don't see, or they don't know." Noreen, for her part, claimed to always present herself as "happy-go-lucky" and to avoid streaming whenever she was in a bad mood.

In some cases, such perceived expectations might lead to cynicism, even for streamers who hope to think of viewers as friends. Camille shared what Goffman [9] referred to as a defensive "backstage image" of her audience that granted her a level of "emotional and moral immunity" (p. 209) for the sake of some social distance. She believed her audience desired positivity and entertainment more than they might want to get to know her as a real person: "As much as they say they like-like genuine-ity, they like authenticity, they like you to be real in front of screen, but in fact, it's that they don't. They don't like the real you. So, you definitely have to put on a persona, for sure." Doing otherwise, she felt, would jeopardize her relationship with her audience and community.

\subsection{Not that kind of woman streamer}

The participants' thoughts and feelings about impressions, persona, and engaging their viewers were woven very closely with their ideas of how women streamers should be. Throughout the interviews, they often referred to a stereotype: a girl or woman who wears revealing clothing, and who sexualizes and/or infantilizes herself during streams to raise viewership and money, regardless of the quality of her content or her skill as a gamer. Camille even used the phrase "boobie streamer", which is just one of the common phrases/terms streamers and audiences use to refer to this stereotype [23];Jayna also cited a recent controversy in the Philippines about "sando streaming" ("tank top streaming"). The threat of being similarly stereotyped and lumped together with women who acted that way was something the participants were aware of from the beginning.

In order to avoid the threat, the participants either thought carefully about how much of their femininity could be expressed on-camera or claimed not to care about the expression at all. Streamers might be like Venice, who shared that she was very careful about what she said and how she looked, or like Jayna, who said she streamed even if she felt "bitchy" or when she had not fixed herself for the day, because "Your content is your gaming, not how you look."

All of the participants shared Jayna's sentiment that their performance as gamers, not as women, should be the audience's main interest. Furthermore, they drew legitimacy not only from streaming gameplay, but from streaming skilled gameplay. Thus, they were more likely to choose games where they already had some expertise. Or, they would make it clear to their viewers that the game was one they were still learning.

Moreover, participants looked down on other women streamers they perceived as relying too much on the so-called female advantage and conforming to the stereotype, because the stereotypical woman streamer threatened their credibility as skilled gamers and made it more difficult for women to gain the legitimacy and acceptance they desired. Camille, for example, expressed disdain for those who primarily 
streamed In Real Life (IRL) content, a now-defunct Twitch category for non-gaming streams. Twitch has since replaced it with various subcategories, including Just Chatting, where many women streamers simply converse with their viewers. Camille believed this sort of content did not belong on Twitch:

People like IRL streamers makes my dream goal a lot further, because people will just keep thinking you are just a female IRL streamer. ... But actually, the essence of Twitch is about showing a different perspective of gaming. ... And I feel that they [IRL streamers] kinda tarnish the Twitch essence.

This desire for legitimacy might also be why the interviews usually began not with the participants' streaming histories, but with their gaming histories. Perhaps they wished to make it clear that they had been gamers long before they had been streamers; they had not simply gone live for money and attention.

\subsection{Local streams trickling into global pools}

As discussed above, finding and cultivating a dedicated community was the main reason to stream. Some participants hoped for that community to include audiences from outside their own countries and cultures. They also recognized that interacting with foreign viewers was an opportunity to be cultural representatives themselves, explaining elements of Filipino or Singaporean life to those watching from farther away. Participants also used platform "raiding" features that would lead or transfer their viewers to other streamers from the local community when their own sessions ended, promoting the exposure of fellow Singaporean/Filipino performers.

Yet, having an audience on the worldwide, million-viewer scale that current top streamers enjoy felt out of reach for the participants. They felt on unequal footing as Asians in a medium perceived as dominated by North America and Europe.

Practically speaking, Bethany noted that the time difference made it difficult for her to reach a more international audience. Most streamers go online at night, after their local audiences would have finished work, studies, and dinner. Being several hours ahead, most Southeast Asian streamers would be online when Western viewers would be at work or school, or just starting their day.

More than this, however, language differences made streamers question whether they would appeal to foreign audiences. Based on both language use in their streams and on their interviews, participants thought English proficiency was important to reach international audiences (and this comes with implicit acceptance of English's general dominance in the world). This might not seem too difficult for women whose countries' education systems are still highly influenced by those of their Anglophone former colonizers, and whose countries continue to score above the global mean in standardized tests of English proficiency [30]. Yet, language and accent remained a source of insecurity.

Platform choice itself seemed related to language. Facebook Gaming might be more appealing for Filipino streamers because $97 \%$ of the Philippines' 76 million social media users have a Facebook account [31], and an audience of potentially millions is still appealing, even if they are all from the same country or culture. Many of the Filipino streamers we observed on Facebook Gaming spoke almost entirely in Tagalog or Taglish. Though they returned greetings and conversed in English if necessary, their audiences were almost exclusively made up of other Filipinos.

For Singaporean participants, their struggles to gain an audience in the global streaming landscape were intertwined with difficulty gaining acceptance as streamers in local Singaporean society. They suggested that the local streaming scene was limited in terms of potential audience as well as performers. Because it was difficult to reach larger, more diverse audiences, the sponsors they could attract were also limited. And, ultimately, until they felt that Singaporean society at large was more accepting of gaming as a profession, it would be difficult for them to justify spending more time playing and trying to grow their audiences. Singapore has what might be considered a mature online influencer industry [32], yet it appears that the work, management, and promotion of streaming and streamers is not as developed.

Neither Filipina participant had similar thoughts about the Philippine e-sports scene, but some cultural observations might suggest how it compares with Singapore at least. The Philippines has a strong, often fanatical celebrity culture and is more open to careers in entertainment and the arts. Professional gaming and streaming might therefore be accepted as simply another venue for aspiring entertainers. Jayna herself belongs to the roster of a Philippine e-sports organization whose roughly 140 streamers include mainstream Philippine media celebrities, including a Miss World pageant winner. 


\section{Discussion}

Women streamers in Singapore and the Philippines began streaming mainly out of a desire to interact with an audience, who would form a community around their gameplay and performance. From the beginning, however, the streamers are wary of how their audience might perceive them, feeling fear and awkwardness in their first streams, then eventually developing a sense of obligation to their public as they become seasoned performers. For some streamers, this obligation entails maintaining a certain presentation of self they believe the audience wants: a happy or cheerful woman who is there to have fun with her viewers. This impression must be maintained regardless of how the streamer is really feeling, and in the case of streamers like Camille and Venice, can lead to questioning whether it is worthwhile to continue streaming at all.

The crafting of a suitable presentation of self for the women streamers in this study is also a highly conscious response to a stereotype about women streamers in general: that women streamers allow themselves to be objectified and sexualized for viewership and money, are less concerned with whether their streamed gameplay is skilled or engaging, and are likely to be worse at gaming in general. As the participants consider themselves to have been gamers long before they were streaming, this stereotype is an extension of the one of inferiority affecting women in general gaming culture, and it is thus a further threat to their legitimacy in that culture. Indeed, it is paradoxical that the increased visibility the participants have gained from streaming and becoming successful streamers might also further expose them to more judgment as "typical girl gamers". These anxieties have been observed in other literature on streaming practices and discourse [23][15].

The women streamers in this study attempted to distinguish themselves from the stereotype with different approaches to the presentation of self. For some, it required careful attention to appearances and speech, to avoid conforming to the stereotype. For others, less care was actually a way of communicating that they cared more about gameplay than their physical appeal.

It is troubling that in attempting to combat being stereotyped, some participants denigrated fellow women streamers they perceived as stereotypical. This can be understood as internalized misogyny, or women reinforcing male-dominant culture through devaluing other women [33]. Recent research has suggested that being long-time gamers themselves might influence girls and women to internalize the misogyny of gaming culture [34], which might explain the responses of some of the participants in this study. However, this same study found that internalized misogyny in a woman gamer could be attenuated by her personal understanding and appreciation of her own femininity. Future work could further explore how women streamers might gain this understanding, incorporate it into their presentations of self, and change the way they relate to fellow women streamers.

As Southeast Asians, specifically Singaporeans and Filipinos, the participants recognize that streaming potentially allows them to reach audiences around the world. They are aware that the languages they use and the interactions they have with foreign viewers allow them to serve as representatives of their cultures. Successfully engaging with foreign viewers and might thus grant streams niche globality, which describes how media productions and performances directed at local audiences find unintended markets abroad [35]. With niche globality, streams can serve as windows to transcultural experiences of other parts of the world. It also indicates a form of cultural capital that distinguishes them for audiences whose online media landscapes that have certain dominant or homogenized aesthetics [36].

However, some participants are not confident in their and their Southeast Asian peers' ability to appeal to foreign audiences, and thus in their potential for niche globality. They perceive inferiority when it comes to their own gaming and streaming in comparison to the Western peers they see as the dominant group in e-sports. This can be a form of colonial mentality, which attributes superiority and desirability to American and other Western cultures, products, etc. [37]. It may be a remnant of Singapore and the Philippines' histories as former British and American colonies, respectively, as well as general global dominance of Western culture, even in gaming culture. Future work could take a more critical approach to examining colonial mentality and potential cultural decolonization among Asian streamers.

The participants experienced tensions regarding women's physical or visual presentation of self similar to those documented in other studies conducted in Western settings [23][7][22]. It was in other areas of their performance that they saw Filipina/Singaporean identity having some influence. Filipina femininity is characterized by being caring, cheerful, emotionally expressive, and playing the gracious hostess or homemaker [27]. This might be why both Noreen and Jayna emphasized fun, happiness, or cheer in relation to being Filipina streamers. Jayna specifically used the word "kengkoy" ("jokester", "jester", or "jester-like") to describe what she saw as the Filipino streamer's 
appeal. On the other hand, the Singaporean streamers tended to view Singaporeanness as a limitation or challenge to being performers at all, especially as they perceived societal pressures to focus on more traditional work or studies. This is consistent with what PuruShotam [26] considers the moderate feminism of Singaporean femininity, where women can recognize inequality and seek personal empowerment, provided they still engage in "responsible familial and national participation" (p. 131 ) in a state the sees itself as not "anti-woman" but "pro-family" (p. 148).

Considering that most of the participants had professional e-sports connections, future research might also explore the e-sports organization/agency ecosystem and its relation to performance and the presentation of self. In devising his framework for the presentation of self, Goffman [9] was interested not only in the performance of the individual but also that of the team. This is because the performance of a certain impression might depend, not only on the person or persons at the focus of the audience's attention, but also on those who play supporting and/or backstage roles to enhance and even constrain that impression. Past research has noted how e-sports production has evolved from informal, participatory events to reinforce traditional sports imagery and presentation, from the way large e-sports events use many of the same techniques as traditional sports broadcasts to the way individual competitors might mimic or be styled after traditional athlete-celebrities [38][39]. New studies could further explore the processes and interactions involved in crafting the impressions of professional players/streamers and their agencies/organizations.

To illustrate, Jayna claimed that her organization had no direct influence on how she conducted her streams. However, we could argue that being identified as an agency talent creates a strong impression of professionalism and status for anyone visiting her page for the first time. And on the other hand, encountering the agency for the first time through Jayna's streams might foster a different impression of that agency than encountering it through, for instance, one of its men talents, or one of its talents who are also mainstream celebrities. The same might be said of corporate streamer partnership programs such as the one Venice was part of. Though she, too, claimed that her sponsor did not directly influence her stream, the graphics indicating her partnership under the company might already impress upon first-time visitors to her stream some of the legitimacy she desired, as the sponsor is renowned among hardcore gamers.
The participants in this study all used streaming platforms established by American companies. Most participants spoke English in their streams, as did most of the streamers whose live broadcasts we viewed, and a few interviewees were concerned with their appeal to Western audiences. However, participants noted other platforms that might be more popular among local and regional audiences. There are also streamers who prefer to stream in their own languages and do not appear interested in an audience beyond their own countrymen. Globality, niche or otherwise, does not appear to be a universal value. Thus, another direction for further studies is to explore the impact of Asian platforms such as Singapore's Bigo, Korea's afreecaTV, and China's Douyu, as well as the communities of non-English streams. Recent work on Douyu has exemplified some of the diversity in streamers' gendered presentation in China alone [40].

Finally, this study focused on streamers who are fairly successful, having reached a large enough audience to earn an income from their streams. We found the streamers included here through Internet searches, browsing the streaming platforms, and following referral links between streamers' pages. However, ranking or recommendation systems might have simply made it more likely for us to find such popular streamers than to find small streamers, or those who stream to a very small audience. Some might stream for months or even years to no audience at all [41]. Future studies could explore the motivations of small but persistent streamers, presenting themselves to audiences they can only imagine.

\section{References}

[1] M. Borowy and D.Y. Jin, "Pioneering e-sport: The experience economy and the marketing of early 1980s arcade gaming contests", International Journal of Communication, USA, 2013, pp. 2254-2274.

[2] S. Fisher, "The amusement arcade as a social space for adolescents: An empirical study", Journal of Adolescence, Elsevier, Netherlands, 1997, pp. 71-86.

[3] M. Griffiths, "The observational study of adolescent gambling in UK amusement arcades", Journal of Community and Applied Social Psychology, Wiley, USA, 1991, pp. 209-320.

[4] R. Rietkerk, "Newzoo Adjusts 2020 Esports Forecast Slightly: The Coronavirus' Short-Term Impact on the Esports Market", https://newzoo.com/insights/articles/newzoocoronavirus-impact-on-the-esports-market-businessrevenues/, 15 April 2020.

[5] B. Egliston, "Watch to win? E-sport, broadcast expertise and technicity in Dota 2", Convergence: The 
International Journal of Research into New Media Technologies, Sage, USA, 2019, pp. 1-20.

[6] M.R. Johnson and J. Woodcock, "The impacts of live streaming and Twitch.tv on the video game industry", Media, Culture \& Society, Sage, USA, 2019, pp. 670688.

[7] T.L. Taylor, Watch me play: Twitch and the rise of game live streaming, Princeton University Press, USA.

[8] J. Kooistra, "Newzoo's trends to watch in 2019", https://newzoo.com/insights/articles/newzoos-trendsto-watch-in-2019/, 3 January 2019

[9] E. Goffman, "The presentation of self in everyday life", Penguin, UK,1959.

[10] P. Chung, "The globalization of game art in Southeast Asia", Routledge Handbook of New Media in Asia (Eds.: L. Hjorth and O. Khoo), Routledge, UK, 2015, pp. 402-415.

[11] A.Y.H. Fung and V. Ho, "Game industries in Asia: Towards an Asian formation of game culture", Routledge Handbook of New Media in Asia (Eds.: L. Hjorth and O. Khoo), Routledge, UK, 2015, pp. $377-$ 390.

[12] E. Gandolfi, "Enjoying death among gamers, viewers, and users: A network visualization of Dark Souls 3's trends on Twitch.tv and Steam platforms", Information Visualization, 2018, Sage, USA, pp. 218238.

[13] W.A. Hamilton, O. Garretson, and A. Kerne, "Streaming on Twitch: Fostering participatory communities of play within live mixed media", In Proceedings of the 32nd annual ACM conference on human factors in computing systems, ACM, USA, 2014, pp. 1315-1324.

[14] A.J. Pellicone and J. Ahn, "The game of performing play: Understanding streaming as cultural production", Proceedings of the 2017 CHI Conference on Human Factors in Computing Systems, ACM, USA, 2017, p. 4863-4874.

[15] T.P.B. Smith, M. Obrist, and P. Wright, "Livestreaming changes the (video) game.", Proceedings of the 11th European Conference on Interactive TV and Video, ACM, USA, 2013, pp. 131-138.

[16] A.M. Manago, M.B. Graham, P.M. Greenfield, and G. Salimkhan, "Self-presentation and gender on MySpace", Journal of Applied Developmental Psychology, Elsevier, Netherlands, 2008, pp. 446-458.

[17] J. Rui and M.A. Stefanone, "Strategic selfpresentation online: A cross-cultural study", Computers in Human Behavior, Elsevier, Netherlands, 2013, pp. 110-118.

[18] L. Bullingham and A.C. Vasconcelos, "The presentation of self in the online world': Goffman and the study of online identities", Journal of Information Science, Sage, USA, 2013, pp. 101-112.

[19] M. Sjöblom and J. Hamari, "Why do people watch others play video games? An empirical study on the motivations of Twitch users", Computers in Human Behavior, Elsevier, Netherlands, 2017, pp. 985-996.

[20] R. Scully-Blaker, J. Begy, M. Consalvo, and S.C. Ganzon, "Playing along and playing for on Twitch:
Livestreaming from ", Proceedings of the 50th Hawaii International Conference on System Sciences, University of Hawaii, USA, 2017.

[21] C. D'Anastasio, "The stereotype that women on Twitch are 'asking for it", https://kotaku.com/thestereotype-that-women-on-twitch-are-asking-for-it1822454131, 26 January 2018.

[22] A. Zolides, "Lipstick bullets: Labor and gender in professional gamer self-branding", Persona Studies, 2015, pp. 42-53.

[23] B. Ruberg, A.L.L. Cullen, and K. Brewster, "Nothing but a 'titty streamer': legitimacy, labor, and the debate over women's breasts in video game live streaming", Critical Studies in Media Communication, Routledge, UK, 2018, pp. 466-481.

[24] A.L.L. Cullen and B. Ruberg, "Necklines and 'naughty bits': Constructing and regulating bodies in live streaming community guidelines", ACM FGD '19, USA, 26-30 August 2019.

[25] C. Abidin and M.L. Brown, Microcelebrity around the globe: Approaches to cultures of Internet fame, Emerald Publishing Limited, UK, 2018.

[26] N. PuruShotam, "Between compliance and resistance: Women and the middle-class way of life in Singapore", Gender and power in affluent Asia (K. Sen and M. Stivens, Eds.), Routledge, UK, 1998, pp. 127-166.

[27] V.V. Valledor-Lukey, "Pagkababae at pagkalalake (femininity and masculinity): Developing a Filipino gender trait inventory and predicting self-esteem and sexism", Child and Family Studies - Dissertations, Syracuse University, USA, 2012.

[28] J.A. Smith, P. Flowers, M. Larkin, Interpretative phenomenological analysis: Theory, method, and research, Sage, USA, 2009.

[29] C. Baker, J. Wuest, and P.N. Stern, "Method slurring: the grounded theory / phenomenology example", Journal of Advanced Nursing, Wiley, USA, 1992, pp. 1355-1360.

[30] Educational Testing Service, "Test and score data summary for TOEFL iBT® tests: January 2018 December 2018 test data”, https://www.ets.org/s/toefl/pdf/toefl_tsds_data.pdf, 2019.

[31] S. Kemp, "Digital 2019: Essential insights into how people around the world use the Internet, mobile devices, social media, and e-commerce", https://hootsuite.com/resources/digital-in-2019, 2019.

[32] C. Abidin, "Influencer extravaganza: commercial 'lifestyle' microcelebrities in Singapore", The Routledge Companion to Digital Ethnography (Eds.: L. Hjorth, H. Horst, H. Galloway, and G. Bell), Routledge, UK, 2017, pp. 158-168.

[33] D.M. Szymanski, A. Gupta, E.R. Carr, and D. Stewart, "Internalized misogyny as a moderator of the link between sexist events and women's psychological distress", Sex Roles, Springer, USA, 2009, pp. 101109.

[34] K.M. McCullough, Y.J. Wong, and N.J. Stevenson, "Female video game players and the protective effect 
of feminist identity against internalized misogyny", Sex Roles, Springer, USA, 2019, pp. 266-276.

[35] R.B. Tolentino, "Niche globality: Philippine media texts to the world", Popular culture co-productions and collaborations in East and Southeast Asia (N. Otmazgin and E. Ben-Ari, Eds.), NUS Press, Singapore, 2013, pp. 150-168.

[36] C. Abidin, Internet celebrity: understanding fame online, Emerald Publishing Limited, UK, 2018.

[37] E.J.R. David and S. Okazaki, "Activation and automaticity of colonial mentality", Journal of Applied Psychology, American Psychological Association, USA, 2010, pp. 850-887.

[38] N. Taylor, "Play to the camera: Video ethnography, spectatorship, and e-sports", Convergence: The Journal of Research into New Media Technologies, Sage, USA, 2016, pp. 115-130.

[39] N.T. Taylor, "Now you're playing with audience power: The work of watching games", Critical Studies in Media Communication, Routledge, UK, 2016, pp. 293-307.

[40] G. Zhang and L. Hjorth, "Live-streaming, games and politics of gender performance: The case of nüzhubo in China", Convergence: The International Journal of Research into New Media Technologies, Sage, USA.

[41] P. Hernandez, "The Twitch streamers who spend years broadcasting to no one", https://www.theverge.com/2018/7/16/17569520/twitc h-streamers-zero-viewers-motivation-community, 16 July 2018. 